\title{
Human granulosa-luteal cells initiate an innate immune response to pathogen-associated molecules
}

\author{
Laila A Ibrahim ${ }^{1,3}$, Joseph M Kramer ${ }^{1,2}$, R Stan Williams ${ }^{1,2}$ and John J Bromfield ${ }^{1,3}$ \\ ${ }^{1}$ D. H. Barron Reproductive and Perinatal Biology Research Program, Gainesville, Florida, USA, ${ }^{2}$ Department of \\ Obstetrics and Gynecology, College of Medicine, University of Florida, Gainesville, Florida, USA, and \\ ${ }^{3}$ Department of Animal Sciences, University of Florida, Gainesville, Florida, USA
}

Correspondence should be addressed to J J Bromfield; Email: jbromfield@ufl.edu

\begin{abstract}
The microenvironment of the ovarian follicle is key to the developmental success of the oocyte. Minor changes within the follicular microenvironment can significantly disrupt oocyte development, compromising the formation of competent embryos and reducing fertility. Previously described as a sterile environment, the ovarian follicle of women has been shown to contain colonizing bacterial strains, whereas in domestic species, pathogen-associated molecules are concentrated in the follicular fluid of animals with uterine infection. The aim of this study is to determine whether human granulosa-luteal cells mount an innate immune response to pathogenassociated molecules, potentially disrupting the microenvironment of the ovarian follicle. Human granulosa-luteal cells were collected from patients undergoing assisted reproduction. Cells were cultured in the presence of pathogen-associated molecules (LPS, FSL-1 and Pam3CSK4) for $24 \mathrm{~h}$. Supernatants and total RNA were collected for assessment by PCR and ELISA. Granulosa-luteal cells were shown to express the molecular machinery required to respond to a range of pathogen-associated molecules. Expression of TLR4 varied up to 15 -fold between individual patients. Granulosa-luteal cells increased the expression of the inflammatory mediators IL1B, IL6 and CXCL8 in the presence of the TLR4 agonist $E$. coli LPS. Similarly, the TLR2/6 ligand, FSL-1, increased the expression of IL6 and CXCL8. Although no detectable changes in CYP19A1 or STAR expression were observed in granulosa-luteal cells following challenge, a significant reduction in progesterone secretion was measured after treatment with FSL-1. These findings demonstrate the ability of human granulosa-luteal cells to respond to pathogen-associated molecules and generate an innate immune response.

Reproduction (2016) 152 261-270
\end{abstract}

\section{Introduction}

Sexually transmitted infections in women of reproductive age are very common in the USA, with most infections occurring in young women aged between 15 and 24 years. The Gram-negative bacteria Chlamydia trachomatis and Neisseria gonorrhoeae are the leading causes of sexually transmitted bacterial infections with a combined total of 3.6 million new cases/year in the USA (277 million worldwide; Centers for Disease Control and Prevention). Pelvic inflammatory disease (PID) is caused primarily by untreated chlamydia or gonorrhea of the upper reproductive tract, with approximately 10-15\% of women with chlamydia developing PID (reviewed in (Mitchell \& Prabhu 2013)). Direct medical expenditures for PID and its sequelae were estimated at $\$ 1.88$ billion in 1998 (Rein et al. 2000). Although PID is a leading cause of gynecological hospitalization of reproductive aged women in the USA, $10 \%$ of PID patients become infertile primarily due to pelvic adhesions and tubal obstruction (Velebil et al. 1995). Although PID is a cause of pelvic pain and infertility, little is known about the effects on the ovary and female gametes. However, it has been shown that patients with PID have reduced follicle numbers and increased cystic follicles and corpora lutea after the resolution of the initial infection (Weiner \& Wallach 1974, Bychkov 1990). Retrospective analysis of patients undergoing fertility treatment suggest that increased endometrial LPS reduces IVF success (Kamiyama et al. 2004). More recently, it has been demonstrated that bacteria can be isolated from the follicular fluid of women undergoing infertility treatment, with the extent of bacterial colonization of the follicle being correlated with the success of fertility treatment (Neuer et al. 1997, Pelzer et al. 2013).

The initial immune response to pathogens is driven by the innate immune system. Innate immune responses to bacteria depend on conserved pathogen-associated molecules being recognized by receptors of the innate immune system, such as Toll-like receptors (TLRs). Tolllike receptors are typically found in hematopoietic immune cells in addition to non-immune cells of the gut, which readily encounter bacteria. Previous work has demonstrated the ability of primary human granulosa-luteal cells (GLCs) to bind LPS (Sanchotello et al. 1992), whereas the granulosa cell line COV434 
Table 1 Primer sequences for PCR.

\begin{tabular}{|c|c|c|c|}
\hline \multirow[b]{2}{*}{ Gene } & \multicolumn{2}{|c|}{ Sequence $\left(5^{\prime}-3^{\prime}\right)$} & \multirow[b]{2}{*}{ Accession number } \\
\hline & Sense & Antisense & \\
\hline$A C T B$ & ACAGAGCСТCGССТTTGCCG & TTGCACATGCCGGAGCCGTT & NM_001101.3 \\
\hline CD14 & САGAАСССТАGАTGСССТGС & CGCGCTCCATGGTCGATA & NM_000591.3 \\
\hline CYP19A1 & GACGTCGCGACTCTAAATTGC & TGGGAGATGAGGGGTCCAAT & NM_000103.3 \\
\hline$\angle L 1 B$ & AACCTCTTCGAGGCACAAGG & GTCCTGGAAGGAGCACTTCAT & NM_000576.2 \\
\hline IL6 & САGTTССТGCAGAAAAAGGCAA & GCTGCGCAGAATGAGATGAG & NM_000600.3 \\
\hline CXCL8 & CAGAGACAGCAGAGCACACA & GGCAAAACTGCACCTTCACA & NM_000584.3 \\
\hline LY96 (MD2) & ACACCTACTGTGGGAGAGAT & CGTCATCAGATCCTCGGCAA & NM_001195797.1 \\
\hline MYD88 & ТССТGСТGСТGСТTСАAGАТ & GACTGСТСGАGСТGСТTACС & NM_001172567.1 \\
\hline PTPRC (CD45) & TGAAAGAGTGAGAGTGGACGA & TTCTGGTGTCTGCCTGCTTC & NM_001267798.1 \\
\hline STAR & TGTCATCAGGGCGGAGCAC & CAGGACCTGGTTGATGATGCT & NM 000349.2 \\
\hline TLR4 & CTGCCACATGTCAGGCCTTAT & AATGCCCACCTGGAAGACTCT & NM_138554.4 \\
\hline
\end{tabular}

possess TLRs and initiate an innate immune response to pathogen-associated molecules (Price et al. 2012). Whether human GLCs can initiate an innate immune response to pathogen-associated molecules and potentially alter the microenvironment of the follicle remains unknown.

We hypothesized that human GLCs isolated from infertility patients would initiate an innate immune response to pathogen-associated molecules similar to those found on sexually transmitted pathogens. Innate immune-mediated changes to the microenvironment of the ovarian follicle may help to further explain infertility associated with PID or sexually transmitted infections.

\section{Materials and methods}

\section{Tissue collection and granulosa-luteal cell isolation}

Human follicular aspirates were collected from women attempting conception through IVF, as well as from oocyte donors, at the University of Florida Reproductive Medicine
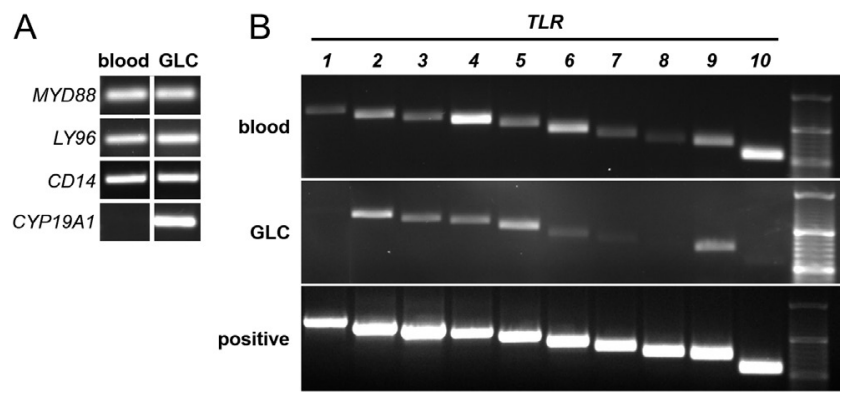

Figure 1 Granulosa-luteal cells express the TLR4 co-receptors and Toll-like receptors required to initiate an innate immune response. GLCs were collected from patients undergoing IVF. (A) After cellular purification, expression of the TLR4 co-receptors MYD88, LY96, and CD14 were assessed by RT-PCR in addition to the granulosa cell-specific marker CYP19A1 (aromatase). (B) Patient GLCs were assessed for the expression of all ten TLRs using RT-PCR after cellular purification. Commercial primer sets were utilized for the detection of individual TLR members. dsDNA was used as positive controls to demonstrate target amplification. RNA collected from whole blood was used as a positive control for all PCR. Each amplification was performed on a minimum of four patient samples.
Clinic. The collection of follicular aspirates for this study was reviewed and approved by the Institutional Review Board at the University of Florida (\#IRB201400399). All patients provided non-written consent to provide tissues as the University of Florida Institutional Review Board considered the follicular aspirates to be non-human waste collected during normal procedures and subsequently discarded and no patient information was obtained. Consenting patients underwent ovarian stimulation using standard long Lupron suppression or GNRH antagonist protocols. Oocyte retrieval was scheduled for $36 \mathrm{~h}$ after administration of an ovulation trigger. After oocytes were collected from the aspirate, the remaining follicular cells were collected by centrifugation at $800 \mathrm{~g}$ for $10 \mathrm{~min}$. Cell pellets were then resuspended in warm PBS and washed by centrifugation at $800 \mathrm{~g}$ for $10 \mathrm{~min}$. Cell pellets were resuspended in complete culture medium containing DMEM: Hams F12 (1:1), 10\% fetal bovine serum, ITS, and $1 \%$ penicillin/streptomycin (all Thermo Fisher Scientific). A 1:1 (vol:vol) Percoll:PBS solution was prepared and the cell suspension layered on top of the Percoll solution and centrifuged at $800 \mathrm{~g}$ for $10 \mathrm{~min}$. Cells were aspirated from a single layer in Percoll and washed in $10 \mathrm{~mL}$ warm PBS by

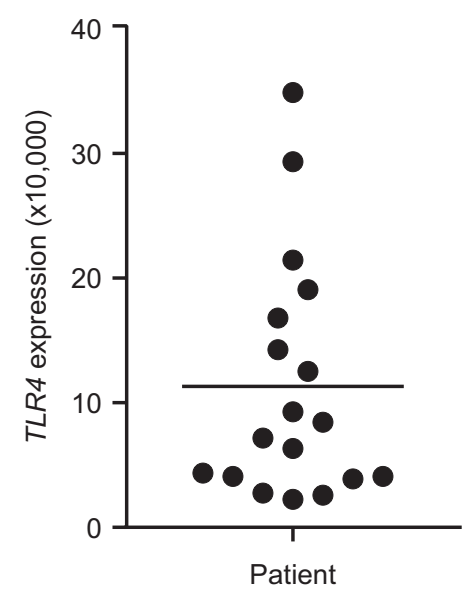

Figure 2 Expression of granulosa-luteal cell TLR4 varies between individual fertility patients. Following cellular purification, expression of TLR4 was assessed in individual patients using real-time RT-PCR. A total of 18 patients were assessed for the expression of TLR4 after confirming cultures were free of immune cell marker. Data were normalized to the housekeeper ACTB. 
A

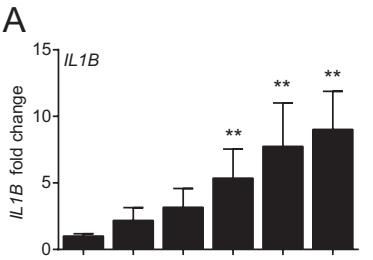

B

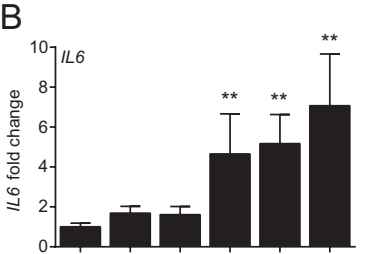

C

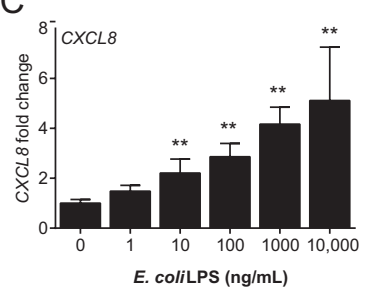

D

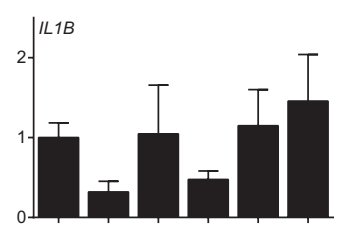

E

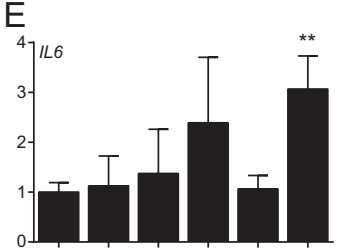

$\mathrm{F}$

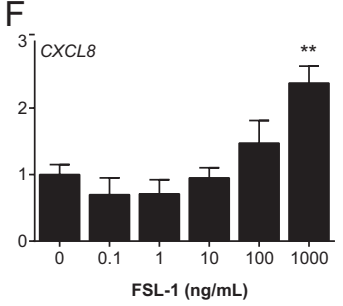

G

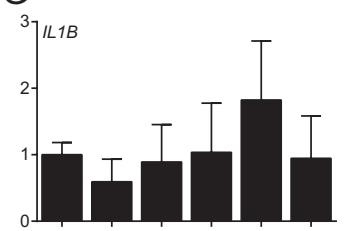

$\mathrm{H}$

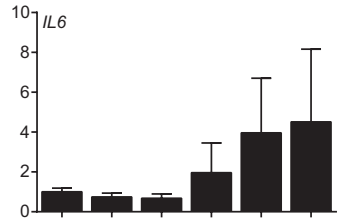

I

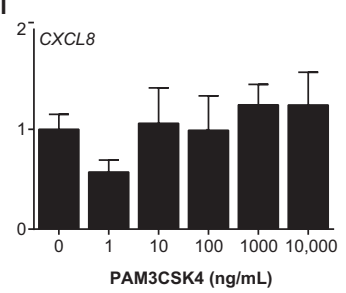

Figure 3 Granulosa-luteal cells increase expression of IL1B, IL6, and CXCL8 in response to pathogen-associated molecules. Following a 24-h treatment of GLCs with tenfold increasing concentrations of E. coli LPS (A, B and C), FSL-1 (D, E and F), or Pam3CSK4 (G, H and I), expression of $I L 1 B$ (A, D and G), IL6 (B, E and $\mathrm{H})$, and CXCL8 (C, F and I) was assessed using real-time RT-PCR. Data are presented as mean \pm S.E.M. from four to eight independent experiments. ${ }^{* *} P \leq 0.05$ compared with untreated controls; analysis by ANOVA followed by Dunnett's pairwise post hoc tests. centrifugation at $800 \mathrm{~g}$. Cellular aggregates of GLCs were disassociated in $1 \mathrm{~mL}$ of $300 \mu \mathrm{g} / \mathrm{mL}$ of hyaluronidase for $10 \mathrm{~min}$ at $37^{\circ} \mathrm{C}$ following a brief vortex. Cells were washed twice in complete medium by centrifugation at $800 \mathrm{~g}$ for $10 \mathrm{~min}$. Cells were resuspended and plated at $10^{5}$ cells $/ \mathrm{mL}$ in $500 \mu \mathrm{L}$ aliquots in 24-well plates (TPP; Switzerland) and incubated at $37^{\circ} \mathrm{C}$ with $5 \% \mathrm{CO}_{2}$ in a humidified environment.

\section{Granulosa-luteal cell culture and challenge}

Granulosa-luteal cells were allowed a 48-h period of equilibration before treatment. Each treatment was performed in a single well and repeated a minimum of four times on different days from different patients. Following $48 \mathrm{~h}$ of culture, medium was replaced with fresh medium containing either ultrapure Escherichia coli O111:B4 LPS (TLR4 agonist; $1 \mathrm{mg} / \mathrm{mL}$ is equivalent to $\left.10^{6} \mathrm{EU} / \mathrm{mL}\right), \mathrm{FSL}-1$ (TLR2/6 agonist; LPS $\leq 0.001 \mathrm{EU} / \mu \mathrm{g})$, Pam3CSK4 (N-palmitoyl-S-[2,3bis(palmitoyloxy)-(2RS)-propyl]-[R]-cysteinyl-[S]-seryl-[S]lysyl-[S]-lysyl-[S]-lysyl-[S]-lysine) (synthetic ligand for TLR1/2; $\mathrm{LPS} \leq 0.001 \mathrm{EU} / \mu \mathrm{g}$ ), or ultrapure Rhodobacter sphaeroides LPS (LPS-RS; TLR4 antagonist) (all from Invivogen, San Diego, CA, USA). Treatments were performed at tenfold increasing doses between $100 \mathrm{pg} / \mathrm{mL}$ and $10 \mu \mathrm{g} / \mathrm{mL}$. After culture for $24 \mathrm{~h}$, cellfree supernatants and total RNA were collected and stored at $-20^{\circ} \mathrm{C}$. A time-course experiment involved the treatment of cells with $100 \mathrm{ng} / \mathrm{mL}$ E. coli LPS between 15 and $360 \mathrm{~min}$.

\section{THP-1 cell line culture}

The human monocyte cell line THP-1 (ATCC, Manassas, VA, USA) was used as a positive control throughout. THP-1 cells were authenticated by ATCC using short tandem repeat (STR) profiling and confirmed a $100 \%$ identity with THP-1 cells according to ATCCs STR database. Cells were cultured in RMPI1640 containing $10 \%$ FCS and $0.05 \mathrm{mM}$ 2-mercaptoethanol. When required, cells were plated at a density of $10^{5} \mathrm{cells} / \mathrm{mL}$ in $500 \mu \mathrm{L}$ aliquots in 24 -well plates and incubated at $37^{\circ} \mathrm{C}$ with $5 \% \mathrm{CO}_{2}$ in a humidified environment. The addition of $50 \mathrm{ng} / \mathrm{mL}$ phorbol myristate acetate (PMA) facilitated the differentiation of monocytes to adherent macrophage-like cells that were used in experimental treatments (Park et al. 2007). Cells were allowed $48 \mathrm{~h}$ for differentiation and equilibration before treatment as per the methods described above.

\section{RNA isolation and PCR}

Cells were washed in warm PBS and lysed in RLT buffer to collect total RNA. Extraction of RNA was performed using the RNA Easy Mini kit according to the manufacturer's instruction (Qiagen). Total RNA was subjected to reverse transcription using the Verso cDNA synthesis kit according to the manufacturer's instruction (Thermo Fisher Scientific). Primers were designed using the NCBI database and initial specificity verified by BLAST to ensure no cross-reactivity with other loci (Table 1). Real-time PCR was performed in $25 \mu \mathrm{L}$ reactions using Maxima SYBR Green chemistry containing $0.5 \mu \mathrm{M}$ of each forward and reverse primer (Thermo Fisher Scientific). A CFX Connect light cycler was employed to perform quantitative PCR (Bio-Rad). Data were normalized independently to ACTB mRNA expression and plotted as expression relative to the mean of the untreated control group using the $\Delta \Delta \mathrm{Ct}$ method. To examine cellspecific markers (PTPRC and CYP19A1) and the presence of receptors required for innate immune recognition of pathogen-associated molecules (MYD88, LY96 and CD14), PCR products were electrophoresed on a $2 \%$ agarose gel containing ethidium bromide and visualized under 

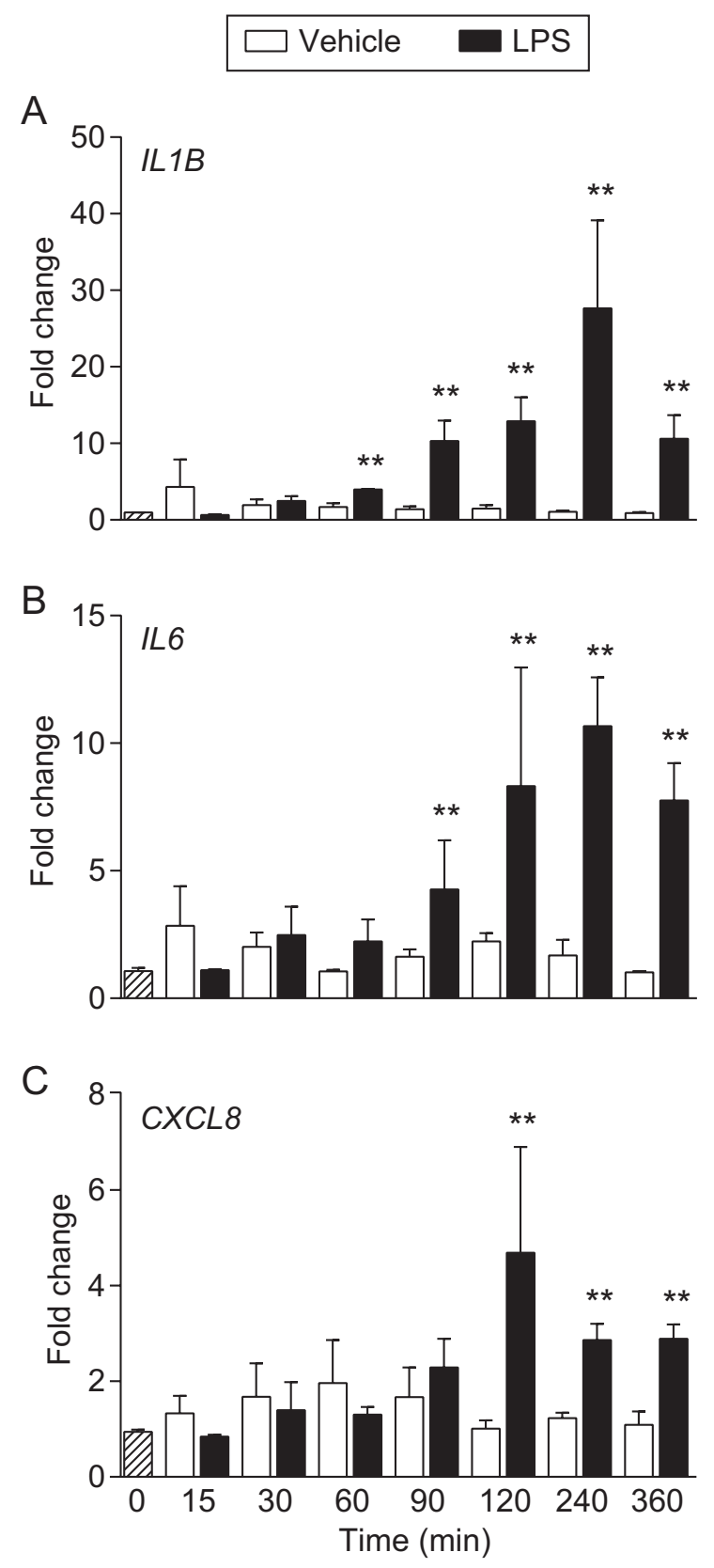

Figure 4 Acute response of granulosa-luteal cells to lipopolysaccharide. Acute responses of GLCs were measured following treatment with $100 \mathrm{ng} / \mathrm{mL}$ E. coli LPS. Cells were treated for 15-360 min before expression of IL1B (A), IL6 (B), and CXCL8 (C) was measured using real-time RT-PCR. Data are presented as mean \pm S.E.M. from three to six independent experiments. ${ }^{* *} P \leq 0.05$ compared with untreated controls; analysis by ANOVA followed by Dunnett's pairwise post hoc tests.

UV illumination. Detection of the TLR family was performed using commercial primer sets from Invivogen according to the manufacturers' instructions and internal positive controls (Invivogen). Whole-blood RNA was purchased and used as an internal control for immune cell markers (Thermo Fisher Scientific).
ELISA

Progesterone and $17 \beta$-estradiol were measured in cellfree supernatants using commercially available ELISA kits according to the manufacturer's instructions (DRG Instruments, $\mathrm{GmbH}$, Germany). The limits of detection for $17 \beta$-estradiol and progesterone were 10.7 and $0.3 \mathrm{pg} / \mathrm{mL}$ respectively; the intra-assay coefficients of variance were 1.1 and $6.4 \%$, and the inter-assay coefficients of variance were 1.2 and $6.63 \%$ respectively.

\section{Immunocytochemistry and fluorescence microscopy}

Cells were plated onto sterile cover glass within 6-well culture plates for $24 \mathrm{~h}$. On the day of labeling, cells were washed twice in warm PBS containing $0.5 \%$ BSA and subsequently blocked in $20 \%$ normal goat serum for $15 \mathrm{~min}$ in the incubator. Cells were again washed in warm PBS+BSA before application of a 1:10 dilution of anti-human CD45-FITC antibody (Miltenyi Biotec, San Diego, CA, USA) in combination with $1 \mu \mathrm{g} / \mathrm{mL}$ Hoechst (Thermo Fisher Scientific) for $30 \mathrm{~min}$ in the incubator. Cells were washed twice in PBS + BSA before immediate live cell image acquisition.

Cells were observed immediately using a Zeiss Axioplan 2 epifluorescence microscope and Axiovision software. Images were acquired using a Zeiss MRm digital camera. A minimum of 200 cells in five separate fields for each sample were assessed for Hoechst staining (total cells) and CD45-positive immunoreactivity (positive cells).

\section{Statistical analysis}

SPSS version 20.0 software was used for statistical analysis. Gene expression measured by real-time RT-PCR and concentrations of steroid hormones were analyzed using ANOVA, and comparisons were made with control using the Dunnett's pairwise post hoc test. If data were not normally distributed, it was log transformed for analysis. Data are arithmetic mean \pm S.E.M., and a $P$ value of $\leq 0.05$ was assumed to be statistically significant.

\section{Results}

\section{Granulosa-luteal cells are free of immune cells}

Contamination of GLCs with immune cells was assessed to ensure that any response measured was due to target cells and not that of contaminating immune cells. Immunocytochemistry was performed to detect immunoreactivity to the immune cell marker PTPRC (CD45). The human monocyte cell line, THP-1, was 91.7\% positive for PTPRC, whereas only $0.45 \%$ of GLCs displayed PTPRC immunoreactivity, suggesting a 99.5\% immune cell marker-free preparation (Supplementary Fig. $1 \mathrm{~A}$ and $\mathrm{B}$, see section on supplementary data given at the end of this article). Following 40 cycles of RT-PCR, expression of PTPRC (CD45) was detected in blood while minimally visible in in GLC cultures 

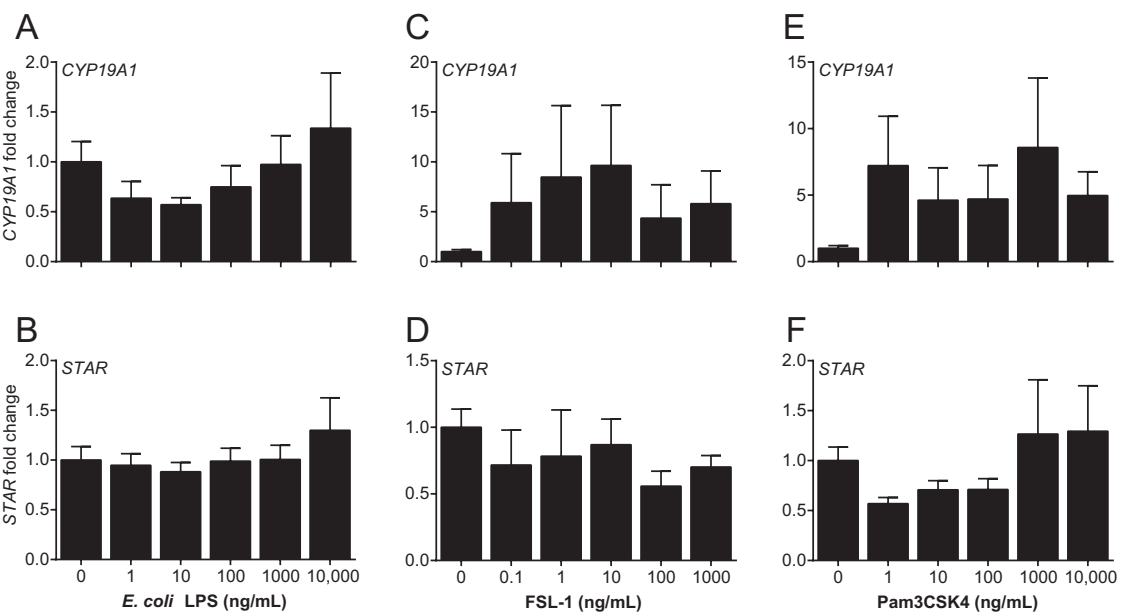

Figure 5 Pathogen-associated molecules do not change expression of CYP19A1 or STAR in granulosa-luteal cells. Following a $24-\mathrm{h}$ treatment of GLCs with tenfold increasing concentrations of E. coli LPS (A and B), FSL-1 (C and D) or Pam3CSK4 (E and F) expression of CYP19A1 (A, C and E) and STAR (B, D and F) was assessed using real-time RT-PCR. Data are presented as mean \pm S.E.M. from four to eight independent experiments. Compared with untreated controls; analysis by ANOVA followed by Dunnett's pairwise post hoc tests.
(Supplementary Fig. 1C). All samples were routinely screened for the presence of PTPRC at the initiation of culture to ensure an immune cell marker-free culture; any cultures shown to express PTPRC were excluded from analysis.

\section{Granulosa-luteal cells express the receptors required to initiate an innate immune response}

Initiation of innate immune signaling is dependent on the presence of TLR co-receptors MYD88, CD14, and LY96 (formerly MD2). Expression of MYD88, LY96, and CD14 were all detected in GLC and blood (Fig. 1A). In addition, the expression of the granulosa cell-specific marker CYP191A (aromatase) was shown to be present in GLCs and absent in blood (Fig. 1A). A PCR screen of all known human TLRs was performed to determine the capacity of GLCs to detect various pathogen-associated molecules. Expression of all ten TLRs was detected in blood, while GLCs had a distinct absence of TLR1and TLR8 expression (Fig. 1B).

Quantitative PCR was used to assess the variable expression of the prototypic receptor, TLR4, on GLCs between 18 individual patients. Analysis showed that GLC expression of TLR4 varied 15-fold between the highest and lowest expressing patients (Fig. 2).

\section{Granulosa-luteal cells increase expression of inflammatory mediators in response to pathogen- associated molecules}

Granulosa-luteal cells were challenged for a period of $24 \mathrm{~h}$ with one of the three pathogen-associated molecules: E. coli LPS (endotoxin, TLR4 agonist), FSL-1 (synthetic lipoprotein, TLR2/6 agonist), or Pam3CSK4 (synthetic triacylated lipopeptide, TLR1/2 agonist). Expression of the proinflammatory cytokines IL1B and IL6 and the chemokine CXCL8 was evaluated. Challenge of GLCs with LPS showed a dose-dependent increase in IL1B, IL6, and CXCL8 expression after $24 \mathrm{~h}$
(Fig. 3A, B and C; $P \leq 0.05$ ). Challenge with FSL-1 showed a significant increase in the expression of IL6 and CXCL8, but only at higher concentrations (Fig. 3D, $\mathrm{E}$ and $\mathrm{F} ; P \leq 0.05)$. Challenge of GLCs with Pam3CSK4 showed some numerical increase in the expression of IL6 (Fig. 3G, H and I; not statistically significant). The human monocyte cell line, THP-1, was also challenged with pathogen-associated molecules under the same conditions as GLCs (Supplementary Fig. 2). THP-1 cells displayed very strong dose response to all three pathogen-associated molecules with increases to $I L 1 B$, IL6 and CXCL8 expression $(P \leq 0.05)$.

\section{Granulosa-luteal cells display an acute response to pathogen-associated molecules}

Using LPS as the prototypical TLR4 agonist, a timecourse experiment was performed to assess the acute responsiveness of GLCs. Following exposure to $100 \mathrm{ng} / \mathrm{mL}$ of LPS, GLCs displayed an increased expression of ILIB by $60 \mathrm{~min}, I L 6$ by $90 \mathrm{~min}$, and CXCL8 by $120 \mathrm{~min}$, which was maintained for $360 \mathrm{~min}$ (Fig. 4). Following treatment for $120 \mathrm{~min}$, expression of IL1B, IL6, and CXCL8 was higher than that observed in GLCs following $24 \mathrm{~h}$ (Fig. 3). The human monocyte cell line, THP-1, had a similar acute response to LPS compared with GLCs (Supplementary Fig. 3). THP-1 cells displayed increased expression of IL1B after $90 \mathrm{~min}$ and elevated CXCL8 after only $60 \mathrm{~min}$. Acute expression of IL6 inTHP-1 cells was muted. THP-1 cells had higher expression of both ILIB and CXCL8 at 240 min compared with $24 \mathrm{~h}$.

\section{Effect of pathogen-associated molecules on granulosa- luteal cell expression of the steroidogenic enzymes CYP19A1 and STAR}

Granulosa cells of bovine have been shown to alter the expression of steroidogenic enzymes after challenge with pathogen-associated molecules (Williams et al. 2008, Price et al. 2013), whereas rats 

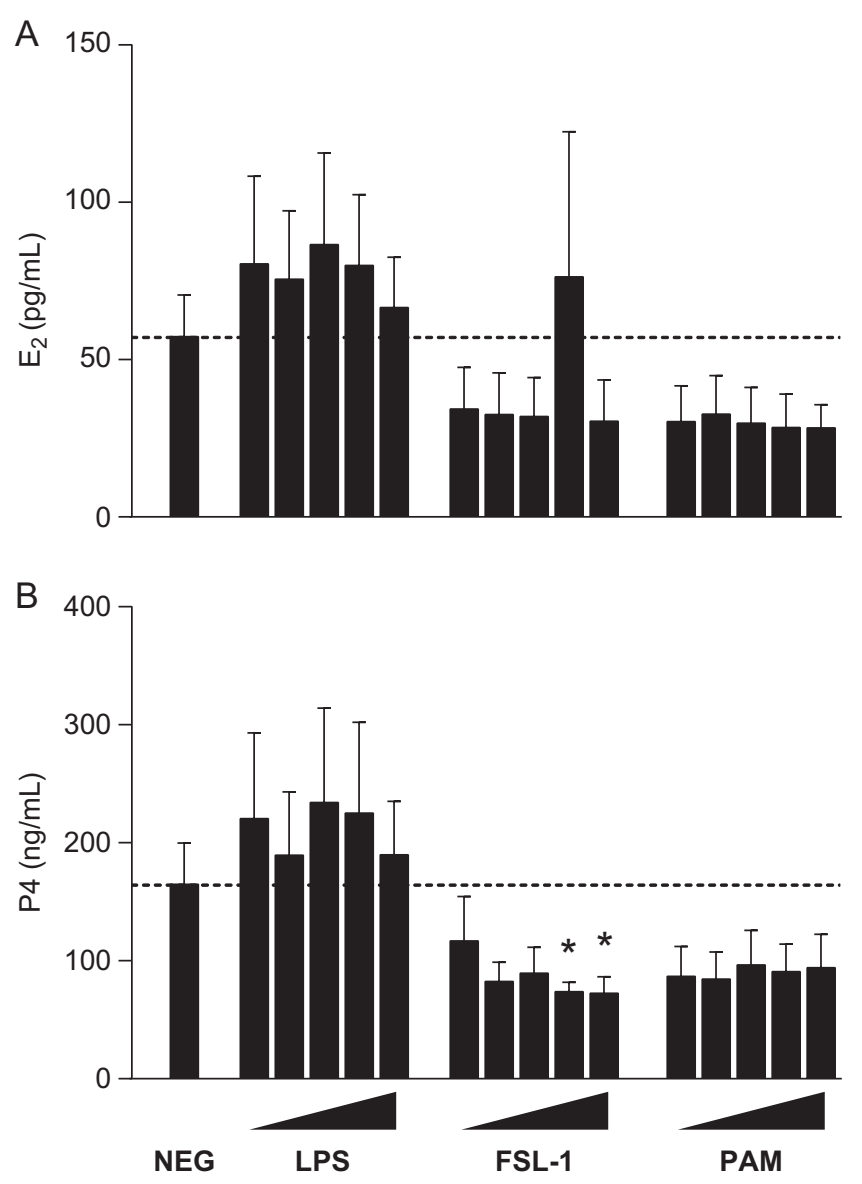

Figure 6 Pathogen-associated molecules alter the accumulation of steroid hormone in granulosa-luteal cells. Following a 24-h treatment of GLCs with tenfold increasing concentrations of E. coli LPS, FSL-1, or Pam3CSK4 (PAM), accumulation of estradiol (A) or progesterone (B) was assessed in cell-free supernatants using ELISA. Data are presented as mean \pm S.E.M. from six independent experiments. $* P \leq 0.08$ compared with untreated controls; analysis by nonparametric Mann-Whitney $U$ test.

reduce estradiol secretion following exposure to LPS (Taylor \& Terranova 1996). Interestingly, the human granulosa cell line (COV343) showed no change after challenge with pathogen-associated molecules (Price et al. 2012). We measured the expression of CYP19A1 and STAR in GLCs following challenge with pathogenassociated molecules (Fig. 5). We did not detect any changes in the expression of either CYP19A1 or STAR following any treatment.

\section{Effect of pathogen-associated molecules on granulosa- luteal cell secretion of $17 \beta$-estradiol and progesterone}

Although no effect on CYP19A1 or STAR expression was observed following exposure of GLCs to pathogenassociated molecules, we measured accumulation of $17 \beta$-estradiol (Fig. 6A) and progesterone (Fig. 6B) in supernatants to confirm any effect on GLC function. Exposure of GLCs to higher concentrations of FSL-1

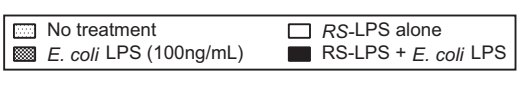

THP-1

GLC
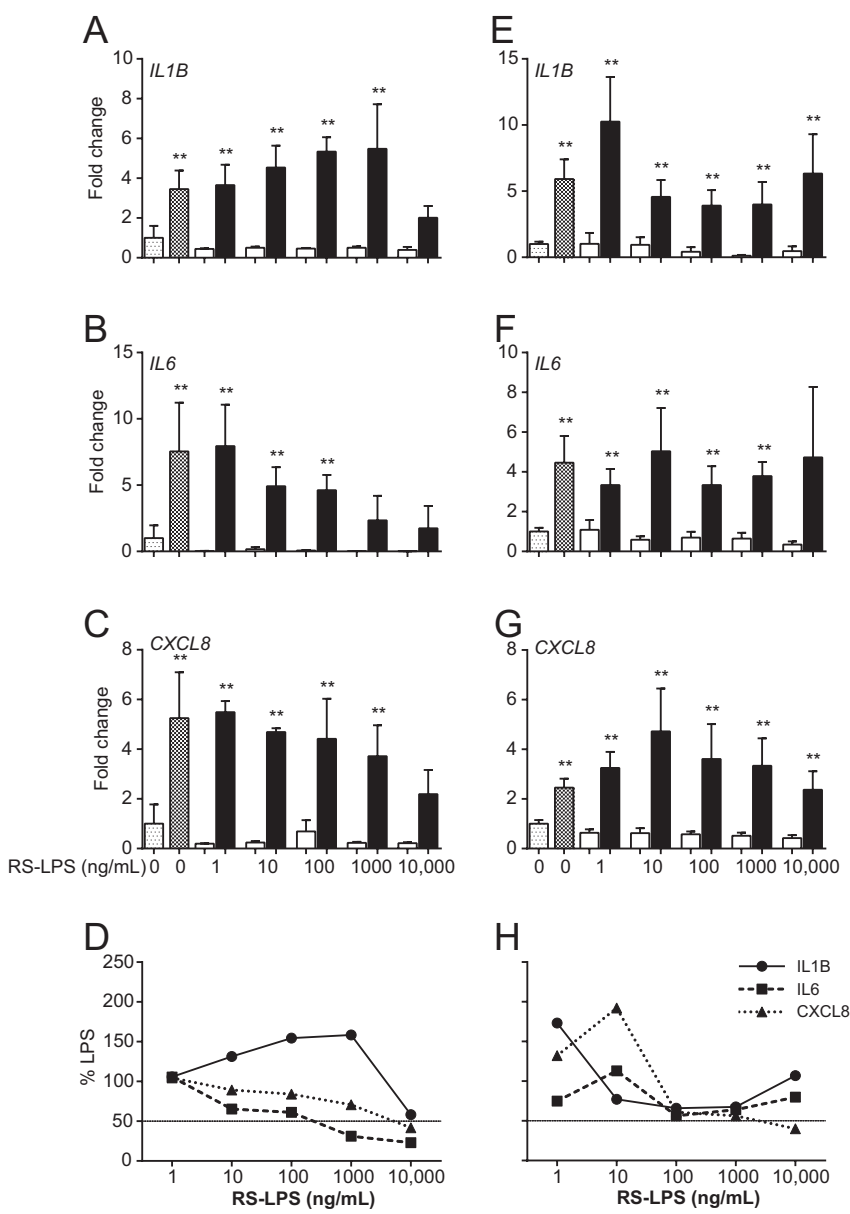

Figure 7 The TLR4 antagonist Rhodobacter sphaeroides LPS does not block the expression of $E$. coli LPS-induced inflammatory mediators in granulosa-luteal cells. GLCs were cultured in the presence of E. coli LPS alone ख, the TLR4 antagonist Rhodobacter sphaeroides LPS alone (RS-LPS; $\square$, RS-LPS in combination with $100 \mathrm{ng} / \mathrm{mL}$ of E. coli LPS $\mathbf{\square}$, or control culture medium $\ldots$. Following a 24-h treatment, the expression of the inflammatory mediators IL1B (A and $\mathrm{E})$, IL6 (B and F), and CXCL8 (C and G) was assessed using real-time RT-PCR in THP-1 cells (A, B, C and D) or GLCs (E, F, G and H). Percent change of expression in cells exposed to RS-LPS in combination with $E$. coli LPS compared with LPS alone are presented for THP-1 (D) and GLCs (H). Data are presented as mean \pm S.E.M. from three to eight independent experiments. ${ }^{*} P \leq 0.05$ compared with untreated controls; analysis by ANOVA followed by Dunnett's pairwise post hoc tests.

reduced progesterone secretion when compared with untreated controls $(2.2$-fold reduction; $P \leq 0.08)$. In addition, exposure of GLCs to either FSL-1 or Pam3CSK4 resulted in a numerical reduction in the secretion of both $17 \beta$-estradiol and progesterone. Challenge of GLCs with LPS had no effect on either $17 \beta$-estradiol or progesterone accumulation. 


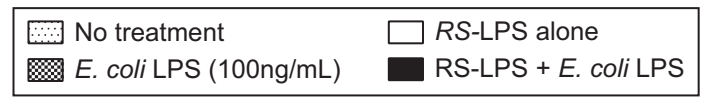

A

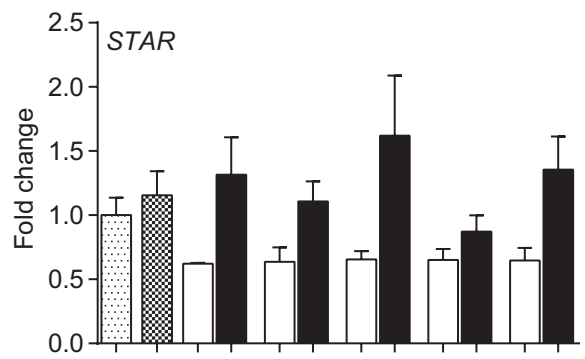

B

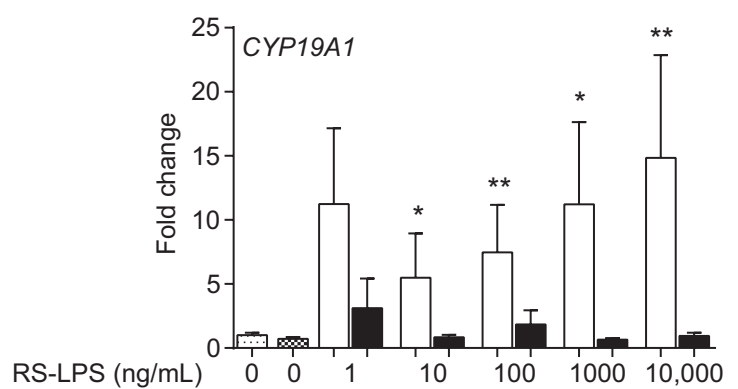

C

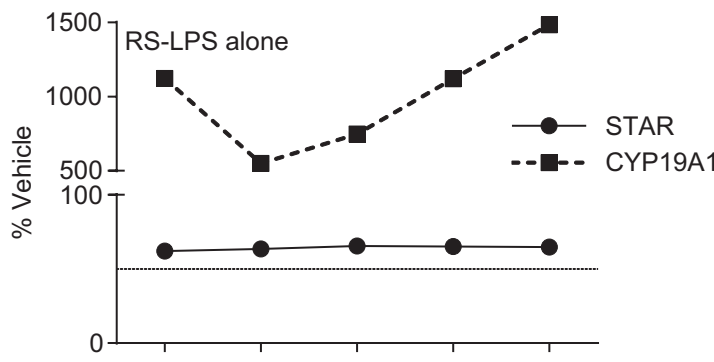

D

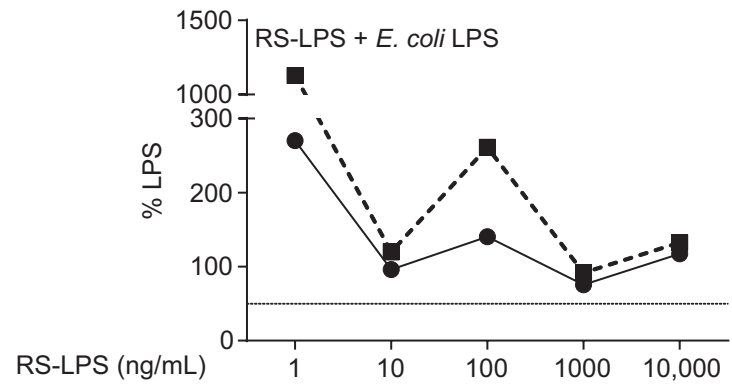

Figure 8 The TLR4 antagonist Rhodobacter sphaeroides LPS increases CYP19A1 expression. GLCs were cultured in the presence of E. coli LPS alone $\circledast$, the TLR4 antagonist Rhodobacter sphaeroides LPS alone (RS-LPS; RS-LPS in combination with $100 \mathrm{ng} / \mathrm{mL}$ of $E$. coli LPS, or control culture medium). Following a 24-h treatment expression of steroidogenic factors, STAR (A) and CYP19A1 (B) expressions were assessed using real-time RT-PCR. Percent change of RS-LPS alonetreated cells compared with untreated controls $(C)$ and RS-LPS treated in combination with $E$. coli LPS compared with LPS alone (D) are presented. Data are presented as mean \pm S.E.M. from three to eight independent experiments. ${ }^{*} P \leq 0.05 ; * P \leq 0.08$ compared with untreated controls; analysis by nonparametric Mann-Whitney $U$ test.
The TLR4 antagonist Rhodobacter sphaeroides LPS did not block expression of E. coli LPS-induced inflammatory mediators

Lipopolysaccharide derived from the bacterium Rhodobacter sphaeroides (RS-LPS) blocks pathogenic LPS/TLR4 activation by competitive binding of the TLR4 co-receptor LY96 (MD2) at 100-fold excess concentrations (Rallabhandi et al. 2012). Here, we attempted to block pathogenic LPS/TLR4 activation by adding RS-LPS in the presence of E. coli-derived LPS and assessing the inflammatory markers above. To confirm the validity of using RS-LPS to block TLR4 signaling, the monocyte cell THP-1 was challenged with $E$. coli LPS in combination with RS-LPS (Fig. 7A, B, C and D). Expression of LPS-induced IL1B, IL6, and CXCL8 was reduced to vehicle-treated control when exposed to a 100-fold excess of RS-LPS in THP-1 cells. Expression of LPS-induced IL1B, IL6, and CXCL8 was reduced to 58.2, 23.1 , and $41.7 \%$ respectively of LPS alone treatment when THP-1 cells were exposed to 100-fold excess of RS-LPS (Fig. 7D). Challenge of GLCs with RS-LPS alone had no effect on the expression of the inflammatory mediators IL1B, IL6, or CXCL8 (Fig. 7E, F, G and H). The addition of RS-LPS did not block the increased expression of $E$. coli LPS-induced inflammatory mediators, even at 100-fold excess concentrations in GLCs. Expression of LPS-induced IL1B, IL6, and CXCL8 was 106.9, 79.9 and $40.0 \%$ respectively of LPS alone-treated GLCs when exposed to 100-fold excess of RS-LPS (Fig. 7H).

\section{The TLR4 antagonist Rhodobacter sphaeroides LPS increases CYP19A1 expression in granulosa-luteal cells}

The expression of GLC STAR was not affected by either E. coli LPS or RS-LPS (Fig. 8A). As previously observed, CYP19A1 expression was not affected in GLCs treated with E. coli LPS alone. However, challenge of GLCs with RS-LPS alone increased the expression of CYP19A1 up to 14.8 -fold over untreated controls (Fig. 8B). When GLCs were treated in combination with $E$. coli LPS and RS-LPS, expression of CYP19A1 was comparable to untreated controls. Expression of RS-LPS-induced CYP19A1 was between 549 and $1485 \%$ of untreated controls (Fig. 8C). Expression of CYP19A1 or STAR in GLCs treated with E. coli LPS alone was comparable to GLC-treated cells in combination with RS-LPS (Fig. 8D).

\section{Discussion}

Infertility associated with the sequelae of bacterial infections of the upper reproductive tract is highly prevalent among women, estimated to represent approximately $20-30 \%$ of all infertility. Previous work has demonstrated that tubal pathologies associated with chlamydia or gonorrhea are the primary cause of infertility in these patients. However, more recent work has demonstrated that bacteria colonize the 
ovarian follicle and that patients suffering PID show ovarian pathologies (Bychkov 1990, Pelzer et al. 2011, Pelzer et al. 2013). The data presented here suggest that GLCs can initiate an innate immune response to pathogen-associated molecules, potentially altering the microenvironment of the follicle. Although it is important to demonstrate the action of GLCs in initiating the immune response from a mechanistic stand point, it is also physiologically relevant as the ovarian follicle is normally replete of hematopoietic immune cells before ovulation when immune cells infiltrate the follicle to aid in the ovulatory process and control tissue damage (Brannstrom et al. 1994). Previous reports indicate that the cellular makeup of preovulatory human follicular fluid contains approximately $10 \%$ macrophages (Baranao et al. 1995), whereas in earlier follicle stages, immune cells are restricted to the ovarian theca (Brannstrom et al. 1993) and corpus luteum after ovulation (Petrovska et al. 1992). The potential of granulosa cells to alter secretion of inflammatory mediators in response to pathogenassociated molecules could alter the follicular environment or affect neighboring follicles. It is intriguing to consider the redundancies that exist between inflammatory pathways active during normal ovarian physiology and innate immune responses to pathogens. It may be that inappropriate activation of these pathways play a role in reducing ovarian function or oocyte quality following infection. A role of the chemokine IL-8 in promoting macrophages migration to preovulatory follicles has been suggested and is considered critical to facilitate the process of ovulation (Runesson et al. 1996). It could be presumed that inappropriate granulosa cell IL-8 secretion could recruit immune cells to the follicle before preparation for ovulation (Goto et al. 1997). Inflammatory mediators such as IL- $1 \beta$ and IL- 6 have been demonstrated to be important to oocyte developmental competence and ovulation, as such inappropriate concentration or temporal expression may have negative consequences on fertility (Machelon et al. 1994, Passos et al. 2016). The TLR4 pathway has also been demonstrated to be important in physiological ovulation in mice, again suggesting that inappropriate activation of the pathway could have negative consequences on ovarian function (Shimada et al. 2008).

Previous work in both bovine (Price et al. 2013) and rodent (Taylor \& Terranova 1996) models indicates that pathogen-associated molecules have the ability to induce changes in granulosa cell steroid hormone production. Although we did not observe any changes in the expression of the steroidogenic enzymes CYP19A1 or STAR in GLCs following challenge with pathogenassociated molecules, we observed a small reduction in progesterone secretion from GLCs treated with the TLR2/6 ligand FSL-1. This discrepancy from previously reported changes to steroid production is likely related to gonadotropin-induced steroid production, which was not examined in these current studies. However, LPS does not alter $\mathrm{FSH}$-induced steroid production in the human granulosa cell line COV343 (Price et al. 2012). Future experiments will determine the effect of pathogenassociated molecules on gonadotropin-dependent steroid hormone production in GLCs. Interestingly here, the TLR4 antagonist (RS-LPS) increased the expression of CYP19A1 in GLCs. Currently, we have no clear explanation for this phenomenon; however, it has been shown that LPS from distinct pathogens can induce different cellular responses in other cell types (Pulendran et al. 2001). The mode of action for RS-LPS in this model system requires further investigation.

Although sexually transmitted infection-induced infertility is of great concern to the human population, animal models demonstrate the significant effect of upper reproductive tract infections on the ovary. Uterine infections are ubiquitous in dairy cows with approximately $40 \%$ of animals suffering significant bacterial uterine infections after parturition, many of which become infertile after the resolution of infection (reviewed in (Sheldon et al. 2009)). Cows that suffer these infections display disrupted ovarian function (Williams et al. 2008), whereas in vitro studies reveal that oocyte maturation is perturbed in the presence of LPS and granulosa cells initiate a significant inflammatory response to pathogen-associated molecules (Herath et al. 2007, Bromfield \& Sheldon 2011). Similarly, in rodent models, exposure to LPS alters steroidogenesis of granulosa cells (Taylor \& Terranova 1996) and significantly reduces the follicular reserve in a TLR4dependent manner (Bromfield \& Sheldon 2013). Currently, there are a limited number of studies that have investigated the effect of upper reproductive tract infections on the ovary in humans.

Studies investigating the effect of pathogen-associated molecules on fertility treatments have demonstrated a clear association between the presence of LPS in culture components, follicular fluid, or menstrual effluent to poor reproductive outcomes (Snyman \& Van der Merwe 1986, Fishel et al. 1988, Nagata \& Shirakawa 1996, Kamiyama et al. 2004). Although these associations have been made in clinical care, it is interesting to see in this study that patients displayed significant variability in the expression of TLR4 in GLCs. Although this study does not have details regarding infection status of patients, which may result in variable expression of TLR4, it is routine for all patients undergoing fertility treatment to be free of any clinical upper reproductive tract infection. However, patient variability may be a result of subclinical infection or various single-nucleotide polymorphisms present in the human populations. Human polymorphisms of TLR4 have been associated with the severity of inflammatory conditions such as asthma and arthritis (Zhang et al. 2011, Perica et al. 2015). Similarly, TLR4 polymorphisms have also been associated with a decreased incidence of infections such as periodontitis (Sellers et al. 2015). 
Although infection of the ovary itself is rare, it is proposed that systemic LPS exposure, or infection of tissues distant from the reproductive tract, can have impacts on the ovary. The presence of LPS-binding protein (LBP) in circulation is indicative of systemic LPS exposure by infection or possibly a "leaky gut wall", which allows the translocation of LPS from the gut to circulation. In women undergoing IVF treatment, a positive correlation between the presence of LBP in circulation and follicular fluid IL-6 accumulation suggests that systemic exposure to LPS affects the follicular microenvironment. The same study revealed a negative correlation between systemic LBP and serum progesterone, similar to what was observed in this study (Tremellen et al. 2015). In dairy cows, bacterial infections of the mammary gland result in altered steroidogenesis, ovarian function, and oocyte quality following natural or induced disease (Lavon et al. 2008, 2011, Roth et al. 2013, Asaf et al. 2014).

Toconclude, human GLCs from fertility patients express the molecular machinery necessary to initiate an innate immune response to pathogen-associated molecules, increasing expression of inflammatory mediators. These studies build on those previously performed in human's investigating systemic endotoxemia and animal models of clinical disease. These data suggest that granulosa cells have the potential to respond to pathogens and consequently alter the microenvironment of the follicle, perturb oocyte quality, and potentially affect subsequently fertility.

\section{Supplementary data}

This is linked to the online version of the paper at http://dx.doi.org/10.1530/REP-15-0573.

\section{Declaration of interest}

The authors have no conflict of interest to report that could be perceived as prejudicing the impartiality of the research reported.

\section{Funding}

This research did not receive any specific grant from any funding agency in the public, commercial or not-for-profit sector.

\section{Ethical approval}

All procedures performed in studies involving human participants were in accordance with the ethical standards of the institutional and/or national research committee and with the 1964 Helsinki declaration and its later amendments or comparable ethical standards.

\section{References}

Asaf S, Leitner G, Furman O, Lavon Y, Kalo D, Wolfenson D \& Roth Z 2014 Effects of Escherichia coli- and Staphylococcus aureus-induced mastitis in lactating cows on oocyte developmental competence. Reproduction 147 33-43. (doi:10.1530/REP-13-0383)

Baranao RI, Dain L, Palak de Fried E \& Rumi LS 1995 Human granulosa cells express HLA-DR antigen and are capable of synthesizing interleukin-1. Hormone and Metabolic Research 27 495-498. (doi:10.1055/s-2007-980010)

Brannstrom M, Mayrhofer G \& Robertson SA 1993 Localization of leukocyte subsets in the rat ovary during the periovulatory period. Biology of Reproduction 48 277-286. (doi:10.1095/biolreprod48.2.277)

Brannstrom M, Pascoe V, Norman RJ \& McClure N 1994 Localization of leukocyte subsets in the follicle wall and in the corpus luteum throughout the human menstrual cycle. Fertility and Sterility $\mathbf{6 1}$ 488-495. (doi:10.1016/S0015-0282(16)56581-9)

Bromfield J] \& Sheldon IM 2011 Lipopolysaccharide initiates inflammation in bovine granulosa cells via the TLR4 pathway and perturbs oocyte meiotic progression in vitro. Endocrinology 152 5029-5040. (doi:10.1210/en.2011-1124)

Bromfield J \& Sheldon IM 2013 Lipopolysaccharide reduces the primordial follicle pool in the bovine ovarian cortex ex vivo and in the murine ovary in vivo. Biology of Reproduction 88 98. (doi:10.1095/ biolreprod.112.106914)

Bychkov V 1990 Ovarian pathology in chronic pelvic inflammatory disease. Gynecologic and Obstetric Investigation $30 \quad 31-33$. (doi:10.1159/000293209)

Fishel S, Jackson P, Webster J \& Faratian B 1988 Endotoxins in culture medium for human in vitro fertilization. Fertility and Sterility 49 108-111. (doi:10.1016/S0015-0282(16)59659-9)

Goto J, Kanayama N, Asahina T, Okada Y, Kobayashi T \& Terao T 1997 Induction of follicular growth by exogenous interleukin-8. Human Reproduction 12 2729-2734. (doi:10.1093/humrep/12.12.2729)

Herath S, Williams EJ, Lilly ST, Gilbert RO, Dobson H, Bryant CE \& Sheldon IM 2007 Ovarian follicular cells have innate immune capabilities that modulate their endocrine function. Reproduction 134 683-693. (doi:10.1530/REP-07-0229)

Kamiyama S, Teruya Y, Nohara M \& Kanazawa K 2004 Bacterial endotoxin in the endometrium and its clinical significance in reproduction. Fertility and Sterility $\mathbf{8 2}$ 805. (doi:10.1016/j.fertnstert.2004.06.030)

Lavon Y, Leitner G, Goshen T, Braw-Tal R, Jacoby S \& Wolfenson D 2008 Exposure to endotoxin during estrus alters the timing of ovulation and hormonal concentrations in cows. Theriogenology 70 956-967. (doi:10.1016/j.theriogenology.2008.05.058)

Lavon Y, Leitner G, Klipper E, Moallem U, Meidan R \& Wolfenson D 2011 Subclinical, chronic intramammary infection lowers steroid concentrations and gene expression in bovine preovulatory follicles. Domestic Animal Endocrinology 40 98-109. (doi:10.1016/j. domaniend.2010.09.004)

Machelon V, Emilie D, Lefevre A, Nome F, Durand-Gasselin I \& Testart J 1994 Interleukin-6 biosynthesis in human preovulatory follicles: some of its potential roles at ovulation. Journal of Clinical Endocrinology and Metabolism 79 633-642. (doi:10.1210/jcem.79.2.7519193)

Mitchell C \& Prabhu M 2013 Pelvic inflammatory disease: current concepts in pathogenesis, diagnosis and treatment. Infectious Disease Clinics of North America 27 793-809. (doi:10.1016/j.idc.2013.08.004)

Nagata Y \& Shirakawa K 1996 Setting standards for the levels of endotoxin in the embryo culture media of human in vitro fertilization and embryo transfer. Fertility and Sterility 65 614-619. (doi:10.1016/S00150282(16)58164-3)

Neuer A, Lam KN, Tiller FW, Kiesel L \& Witkin SS 1997 Humoral immune response to membrane components of Chlamydia trachomatis and expression of human $60 \mathrm{kDa}$ heat shock protein in follicular fluid of in-vitro fertilization patients. Human Reproduction 12 925-929. (doi:10.1093/humrep/12.5.925)

Park EK, Jung HS, Yang HI, Yoo MC, Kim C \& Kim KS 2007 Optimized THP-1 differentiation is required for the detection of responses to weak stimuli. Inflammation Research 56 45-50. (doi:10.1007/s00011-0076115-5)

Passos JR, Costa JJ, da Cunha EV, Silva AW, Ribeiro RP, de Souza GB, Barroso PA, Dau AM, Saraiva MV, Goncalves PB et al. 2016 Protein and 
messenger RNA expression of interleukin 1 system members in bovine ovarian follicles and effects of interleukin 1 beta on primordial follicle activation and survival in vitro. Domestic Animal Endocrinology 54 48-59. (doi:10.1016/j.domaniend.2015.09.002)

Pelzer ES, Allan JA, Cunningham K, Mengersen K, Allan JM, Launchbury T, Beagley K \& Knox CL 2011 Microbial colonization of follicular fluid: alterations in cytokine expression and adverse assisted reproduction technology outcomes. Human Reproduction 26 1799-1812. (doi:10.1093/humrep/der108)

Pelzer ES, Allan JA, Waterhouse MA, Ross T, Beagley KW \& Knox CL 2013 Microorganisms within human follicular fluid: effects on IVF. PLOS ONE 8 e59062. (doi:10.1371/journal.pone.0059062)

Perica M, Vidovic M, Lamot L, Bukovac LT, Kapitanovic S, Peric M, Barbic J \& Harjacek M 2015 Single nucleotide polymorphism of toll-like receptor 4 (TLR4) is associated with juvenile spondyloarthritis in Croatian population. Clinical Rheumatology 34 2079-2086. (doi:10.1007/s10067-015-2952-8)

Petrovska M, Sedlak R, Nouza K, Presl J \& Kinsky R 1992 Development and distribution of the white blood cells within various structures of the human menstrual corpus luteum examined using an image analysis system. American Journal of Reproductive Immunology 28 77-80. (doi:10.1111/aji.1992.28.issue-2)

Price JC, Cronin J \& Sheldon IM 2012 Toll-like receptor expression and function in the COV434 granulosa cell line. American Journal of Reproductive Immunology 68 205-217. (doi:10.1111/aji.2012.68. issue-3)

Price JC, Bromfield JJ \& Sheldon IM 2013 Pathogen-associated molecular patterns initiate inflammation and perturb the endocrine function of bovine granulosa cells from ovarian dominant follicles via TLR2 and TLR4 pathways. Endocrinology 154 3377-3386. (doi:10.1210/en.2013-1102)

Pulendran B, Kumar P, Cutler CW, Mohamadzadeh M, Van Dyke T \& Banchereau J 2001 Lipopolysaccharides from distinct pathogens induce different classes of immune responses in vivo. Journal of Immunology 167 5067-5076. (doi:10.4049/jimmunol.167.9.5067)

Rallabhandi P, Phillips RL, Boukhvalova MS, Pletneva LM, Shirey KA, Gioannini TL, Weiss JP, Chow JC, Hawkins LD, Vogel SN et al. 2012 Respiratory syncytial virus fusion protein-induced toll-like receptor 4 (TLR4) signaling is inhibited by the TLR4 antagonists Rhodobacter sphaeroides lipopolysaccharide and eritoran (E5564) and requires direct interaction with MD-2. MBio 3 e00218-12. (doi:10.1128/ mbio.00218-12)

Rein DB, Kassler WJ, Irwin KL \& Rabiee L 2000 Direct medical cost of pelvic inflammatory disease and its sequelae: decreasing, but still substantial. Obstetrics \& Gynecology 95 397-402. (doi:10.1097/00006250200003000-00016)

Roth Z, Dvir A, Kalo D, Lavon Y, Krifucks O, Wolfenson D \& Leitner G 2013 Naturally occurring mastitis disrupts developmental competence of bovine oocytes. Journal of Dairy Science 96 6499-6505. (doi:10.3168/ jds.2013-6903)

Runesson E, Bostrom EK, Janson PO \& Brannstrom M 1996 The human preovulatory follicle is a source of the chemotactic cytokine interleukin-8. Molecular Human Reproduction 2 245-250. (doi:10.1093/ molehr/2.4.245)
Sanchotello M, Chen TY, Clinton TK, Lyles R, Moreno RF, Tilzer L, Imakawa K \& Terranova PF 1992 Evidence for lipopolysaccharide binding in human granulosa-luteal cells. Journal of Endocrinology 135 571-578. (doi:10.1677/joe.0.1350571)

Sellers RM, Payne JB, Yu F, LeVan TD, Walker C \& Mikuls TR 2015 TLR4 Asp299Gly polymorphism may be protective against chronic periodontitis. Journal of Periodontal Research 51 203-211. (doi:10.1111/ jre.12299)

Sheldon IM, Cronin J, Goetze L, Donofrio G \& Schuberth HJ 2009 Defining postpartum uterine disease and the mechanisms of infection and immunity in the female reproductive tract in cattle. Biology of Reproduction 81 1025-1032. (doi:10.1095/biolreprod.109.077370)

Shimada M, Yanai Y, Okazaki T, Noma N, Kawashima I, Mori T \& Richards JS 2008 Hyaluronan fragments generated by sperm-secreted hyaluronidase stimulate cytokine/chemokine production via the TLR2 and TLR4 pathway in cumulus cells of ovulated COCs, which may enhance fertilization. Development 135 2001-2011. (doi:10.1242/ dev.020461)

Snyman E \& Van der Merwe JV 1986 Endotoxin-polluted medium in a human in vitro fertilization program. Fertility and Sterility 46 273-276. (doi:10.1016/S0015-0282(16)49525-7)

Taylor CC \& Terranova PF 1996 Lipopolysaccharide inhibits in vitro luteinizing hormone-stimulated rat ovarian granulosa cell estradiol but not progesterone secretion. Biology of Reproduction 54 1390-1396. (doi:10.1095/biolreprod54.6.1390)

Tremellen K, Syedi N, Tan S \& Pearce K 2015 Metabolic endotoxaemia a potential novel link between ovarian inflammation and impaired progesterone production. Gynecological Endocrinology 31 309-312. (doi:10.3109/09513590.2014.994602)

Velebil P, Wingo PA, Xia Z, Wilcox LS \& Peterson HB 1995 Rate of hospitalization for gynecologic disorders among reproductive-age women in the United States. Obstetrics \& Gynecology 86 764-769. (doi:10.1016/0029-7844(95)00252-M)

Weiner S \& Wallach EE 1974 Ovarian histology in pelvic inflammatory disease. Obstetrics \& Gynecology 43 431-437.

Williams EJ, Sibley K, Miller AN, Lane EA, Fishwick J, Nash DM, Herath S, England GC, Dobson H \& Sheldon IM 2008 The effect of Escherichia coli lipopolysaccharide and tumour necrosis factor alpha on ovarian function. American Journal of Reproductive Immunology 60 462-473. (doi:10.1111/j.1600-0897.2008.00645.x)

Zhang Q, Qian FH, Zhou LF, Wei GZ, Jin GF, Bai JL \& Yin KS 2011 Polymorphisms in toll-like receptor 4 gene are associated with asthma severity but not susceptibility in a Chinese Han population. Journal of Investigational Allergology \& Clinical Immunology 21 370-377.

Received 2 December 2015

First decision 22 December 2015

Revised manuscript received 15 June 2016

Accepted 4 July 2016 